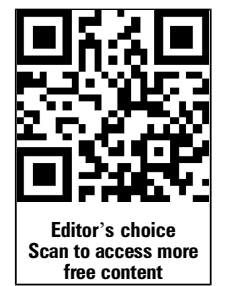

${ }^{1}$ Australian National University Medical School, Canberra, Australian Capital Territory, Australia

${ }^{2}$ Department of Neonatology, Canberra Hospital, Canberra, Australian Capital Territory, Australia

\section{Correspondence to} Alison Kent, Department of Neonatology, Canberra Hospital, PO Box 11, Woden, 2606 ACT, Australia; alison.kent@act.gov.au

Received 25 June 2013 Revised 11 September 2013 Accepted 18 September 2013 Published Online First 18 October 2013

\title{
Antenatal steroid exposure and outcomes of very premature infants: a regional cohort study
}

\author{
D Wong, ${ }^{1}$ ME Abdel-Latif, ${ }^{1,2}$ AL Kent, ${ }^{1,2}$ for the NICUS Network
}

\section{ABSTRACT}

Objective To compare mortality, short-term morbidity and long-term neurodevelopmental outcomes of $<29$ week premature infants with antenatal steroid exposure (none, incomplete and complete).

Patients and methods Multicentre retrospective cohort study, within a geographically defined area in Australia served by a network of 10 neonatal intensive care units (NICUs), of infants $<29$ weeks gestational age, admitted to NICUs between 1998 and 2004. Outcome measures included hospital survival, perinatal complications and functional disability at $2-3$ years follow-up.

Results 2549 neonates were included; 319 (12.5\%) received no exposure to steroids. Hospital mortality (OR $0.59,95 \% \mathrm{Cl} 0.45$ to $0.76, p<0.001$, intraventricular haemorrhage (IVH) $(\mathrm{OR} 0.58,95 \% \mathrm{Cl} 0.42$ to 0.81 , $\mathrm{p}=0.001$ ) and necrotising entercolitis (NEC) (OR 0.62 , $95 \% \mathrm{Cl} 0.42$ to $0.91, p=0.018$ ) was less likely in infants with any steroid exposure. Any steroid exposure was associated with less need for surfactant (OR 0.41, $95 \% \mathrm{Cl} 0.30$ to $0.57, \mathrm{p}<0.001)$ and mechanical ventilation (OR $0.30,95 \% \mathrm{Cl} 0.17$ to $0.52, p<0.001$ ). Subgroup analyses demonstrated differences in outcomes only with complete steroid coverage and not with incomplete coverage. Survival benefit and reduction in the incidence of severe IVH was evident from 24 to 28 weeks. Long-term neurodevelopmental data available for 1473 survivors showed no significant difference in outcomes with steroid exposure after multivariate analysis.

Conclusions Exposure to a complete course of antenatal steroids is associated with higher infant survival rates, lower rates of severe IVH and NEC compared to an incomplete course or no exposure. Any exposure to steroids reduces the risk of moderate cerebral palsy, however, long-term neurodevelopmental outcome may not be affected by steroid exposure.

\section{INTRODUCTION}

It has long been established that administration of antenatal corticosteroids is associated with reductions in adverse health outcomes in premature infants due to the acceleration of fetal lung maturation caused by corticosteroids. ${ }^{1}$

The first randomised control trial of antenatal betamethasone by Liggins and Howie showed reduced mortality rates and respiratory distress syndrome (RDS) in premature infants. ${ }^{1}$ Subsequent randomised control trials have demonstrated that antenatal corticosteroid exposure leads to decreased mortality in premature infants born between 28 and 36 weeks' gestation. ${ }^{2}{ }^{3}$ A Cochrane review of trials has also categorically demonstrated that antenatal steroids reduce the occurrence of major

\section{What is already known on this topic}

- Antenatal steroids are known to improve neonatal survival and to reduce short-term morbidities in extremely premature infants.

- There is limited data from large cohort studies comparing survival, short-term and long-term outcomes with and without steroid exposure.

\section{What this study adds}

- Antenatal steroids given to infants born $<29$ weeks still confer a survival benefit and reduces the likelihood of necrotising enterocolitis and severe intraventricular haemorrhage.

- Antenatal steroids may not have an impact on long-term neurodevelopmental outcomes, but further studies are required.

neonatal morbidities, such as RDS, intraventricular haemorrhage (IVH), necrotising enterocolitis (NEC); antenatal steroids also reduce the need for respiratory support and intensive care admissions. ${ }^{3}$

Neonatal intensive care entails considerable burden on the infant and family; the significant rates of disability in surviving premature infants suggest that this burden continues long after hospital discharge. ${ }^{4}$ When counselling parents of infants at borderline viability, in the context of instigating intensive care, the likelihood of survival, perinatal complications and adverse long-term outcomes are important concerns. Over the past few decades, the use of antenatal corticosteroids has increased and now comprises routine care to those mothers likely to deliver prematurely. For these reasons, it is pertinent to qualify these outcomes in relation to antenatal steroid exposure, to supplement what is presently known of the likelihood of adverse outcomes in premature infants.

Currently, there are large-scale studies of extremely preterm infants that examine survival and neurodevelopmental outcomes in relation to gestational age and birth weight, ${ }^{5}{ }^{6}$ However, there is a paucity of information qualifying outcomes in relation to antenatal corticosteroid exposure. Two recent cohort studies compare mortality and perinatal morbidity outcomes according to antenatal steroid exposure, with stratification for gestational age. These studies showed reductions in mortality, ${ }^{78}$ rates of RDS and severe 
IVH. ${ }^{8}$ However, they did not describe long-term neurodevelopmental outcomes, or the duration of exposure. Existing population studies demonstrate that neurosensory outcomes in extremely premature infants have generally improved over time. ${ }^{5}$ Studies conducted after the advent of antenatal corticosteroids examined neurosensory outcomes, cognitive ability, scholastic achievement and physical development following antenatal steroid administration, with follow-up of children at 5 through to 12 years of age. These demonstrated no significant differences in outcomes when compared with no steroid exposure. ${ }^{9-11}$ However, Doyle et al, ${ }^{12}$ has described better cognitive function in steroid-treated infants compared with non-steroid-treated premature infants. At present, there are no gestational age-stratified multicentre cohort studies that compare mortality, short-term morbidity and long-term outcomes in extremely preterm infants with and without antenatal steroid exposure.

The aims of this study were to compare mortality rates, shortterm morbidity and long-term neurodevelopmental outcomes in infants with their antenatal steroid exposure (none, incomplete, complete), when born less than 29 weeks' gestation, in a large geographically defined Australian population. We hypothesised that any antenatal steroid exposure would improve infant mortality, reduce short-term morbidity and improve long-term neurodevelopmental outcomes.

\section{METHODS}

\section{Study population and data source}

This is a retrospective population-based study of premature infants treated in 10 NICUs in New South Wales (NSW) and the Australian Capital Territory (ACT). The Neonatal Intensive Care Units Data Collection is an ongoing prospective audit of infants admitted to the 10 NICUs in ACT and NSW; definitions and accuracy of this data have been examined elsewhere. ${ }^{13}$ The Neonatal Intensive Care Units Follow-up Data Collection (NICUS) is an ongoing statewide audit of admitted infants, at 2-3 years of age, corrected for prematurity. Approval was obtained from the NICUS study coordinator, and was approved by the ACT Health Human Research Ethics Committee (ETHLR.11.229).

All infants admitted to these NICUs between 1 January 1998 and 31 December 2004, born at less than 29 weeks gestational age were included. Infants with major congenital malformations, or known syndromes that would impact on neurodevelopment, were excluded. Neonates who were not, or could not be, resuscitated in the delivery room were also excluded from the study.

\section{Definitions}

\section{Antenatal steroid exposure}

Antenatal steroid regimens consist of betamethasone, two doses of $12 \mathrm{mg}$ given intramuscularly $24 \mathrm{~h}$ apart, or dexamethasone, four doses of $6 \mathrm{mg}$ given intramuscularly $12 \mathrm{~h}$ apart. A complete course of antenatal steroids was considered if all doses of steroids were received $48 \mathrm{~h}$ prior to delivery but less than 7 days before birth. An incomplete course of steroids was defined as those infants receiving less than $24 \mathrm{~h}$ steroid coverage prior to delivery. Infants given a course of steroids more than 7 days before birth were also considered as having a complete course of steroids.

\section{Survival and short-term morbidity outcome measures}

Mortality was defined as death before hospital discharge from NICU. Short-term outcomes included chronic lung disease (CLD), defined as requiring oxygen supplementation at 36 weeks postmenstrual age; NEC was staged according to Bell's classification, ${ }^{14}$ with diagnostic criteria previously described ${ }^{15}$; IVH was graded $1-4$ by Papile's system ${ }^{16}$; retinopathy of prematurity was staged I-IV according to international criteria ${ }^{17}$; presence of proven systemic infection was also examined. Also included were interventions, such as surfactant therapy, mechanical ventilation duration and length of stay in the NICU.

\section{Long-term outcome measures}

Long-term outcomes were reviewed at 2-3 years of age. Surviving children were offered a formal developmental assessment at 2-3 years age; with protocols detailed previously. ${ }^{18}$ Included were assessment of hearing, vision, neurological examination and developmental assessment using Griffiths Mental Development Scales (GMDS), scored by General Quotient (GQ) or the Mental Scale of the Bayley Scales of Infant Development-II (BSIDII), scored by Mental Development Index (MDI). Child height, weight and head circumference were also measured at follow-up. Long-term neurodevelopment outcomes were qualified as four groups of functional disability (FD) based on the presence of developmental delay (quantified by BSID-II or GMDS developmental scales), cerebral palsy (CP), hearing loss and blindness as previously described. ${ }^{18}$ Moderate/severe FD was defined as one or more of the following: developmental delay $(<2 S D$ below the mean for adjusted age determined by the GMDS or BSID-II), CP (unable to walk without aids), bilateral blindness (visual acuity $<6 / 60$ in better eye), or bilateral deafness (requiring bilateral hearing aids or cochlear implants.

\section{Statistical analysis}

Statistical analyses were performed using the Predictive Analytics SoftWare (PASW) (PASW for Windows; Release V.18.0.2. SPSS: An IBM Company; Chicago, Illinois, USA, 2010). Data are presented as number and percentage with OR and 95\% CI or median and IQR. Maternal and perinatal characteristics were compared using $\chi^{2}$ test with continuity correction and test where appropriate. Adjusted differences in survival and neurodevelopmental outcomes between those receiving and not receiving a complete course of steroids were estimated using multiple logistic regression models. These models were adjusted for significant and clinically important baseline population characteristics including maternal age, pregnancy-induced hypertension, gestational age, birth weight, gender, outborn status and assisted conception. Cut-off for entry to and removal from models was set at $p<0.05$ and $p>0.10$. The level of significance for all sets of analysis was set at $\mathrm{p}<0.05$ using 2-tailed comparisons. Significance levels were not adjusted for multiple comparisons performed. ${ }^{19}$

\section{RESULTS}

A total of 2701 infants were admitted to the NICUs during the study period; 152 were excluded with major congenital abnormalities leaving 2549 infants; 319 (12.5\%) infants had no steroid exposure, $2230(87.5 \%)$ infants recorded any or complete steroid exposure. Follow-up data at 2-3 years was obtained for 1473 infants ( $74.8 \%$ of those eligible for follow-up). Of these infants, $1323(89.8 \%)$ children had received antenatal steroids (figure 1).

\section{Profile of infants lost to follow-up}

Infants numbering 497 were lost to follow-up. Those lost to follow-up were more likley to be of aboriginal ethnicity $(7.3 \%$ vs $1.4 \%, \mathrm{p}<0.001)$ and outborn $(16.5 \%$ vs $7.4 \%, \mathrm{p}<0.001)$. Infants lost to follow-up had a higher median birth weight (1029 vs $945 \mathrm{~g}, \mathrm{p}<0.001)$ and were less likely to require surfactant therapy $(60.2 \%$ vs $71.4 \%, p<0.001)$ or mechanical ventilation $(77.3 \%$ vs $87.3 \%, \mathrm{p}<0.001)$. In those lost to follow-up, proven systemic infection was less likely $(28.8 \%$ vs $40.4 \%$, $\mathrm{p}<0.001)$ as was $\operatorname{CLD}(26.8 \%$ vs $40.5 \%, \mathrm{p}<0.001)$, and the 


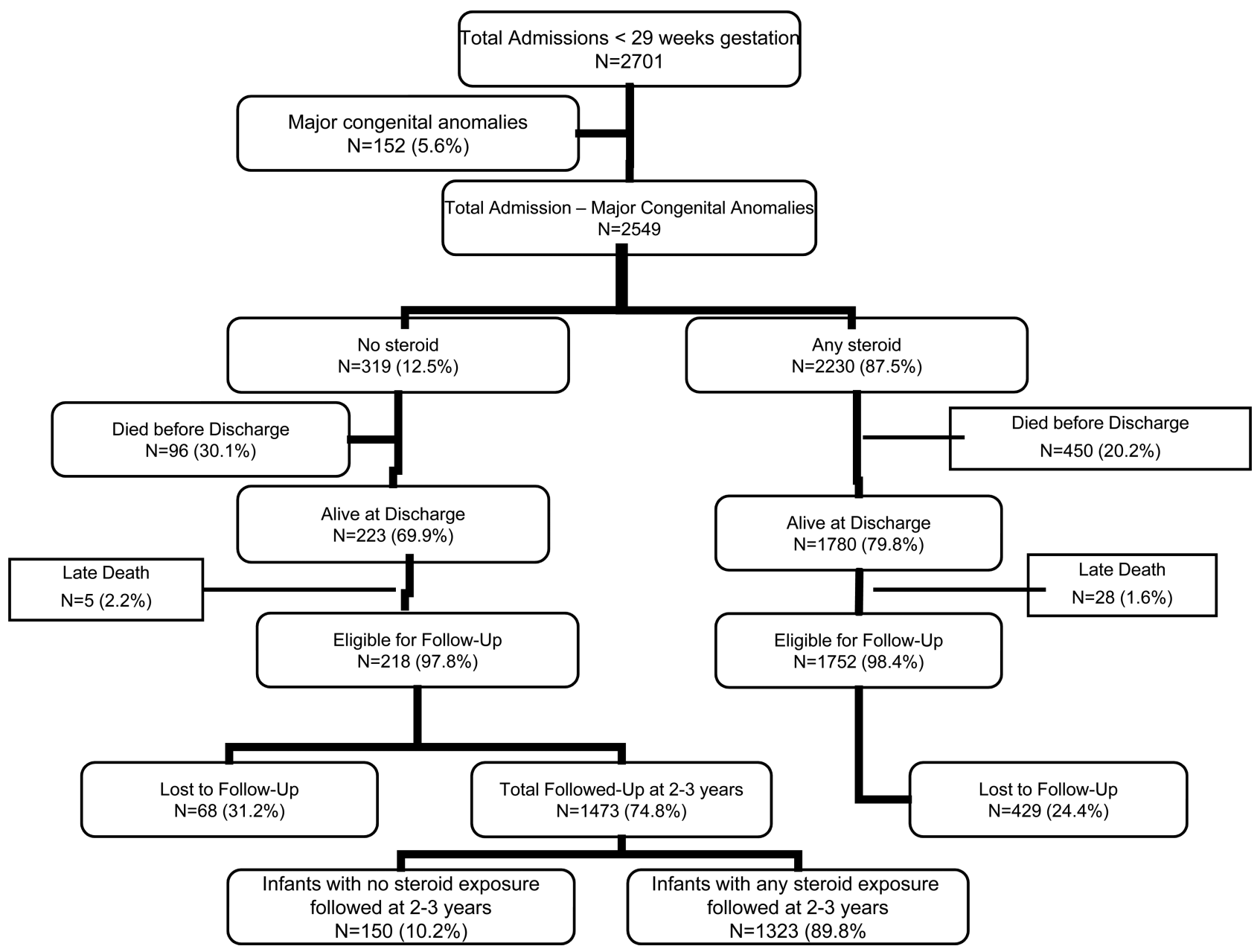

Figure 1 Profile of infants from birth to follow-up among infants admitted to NICUs between 1998 and 2004, with and without steroid exposure.

use of postnatal steroids for treatment of CLD $(15.7 \%$ vs $27.7 \%, \mathrm{p}<0.001)$ when compared with those followed-up. Infants not followed-up had significantly shorter stays in intensive care $(74$ vs 82 days, $\mathrm{p}<0.001)$ (data not shown).
Perinatal and neonatal characteristics of infants according to steroid exposure

Infants with no steroid exposure had lower median gestational age ( 26.0 vs $27.0 \mathrm{wks}, \mathrm{p}=0.012)$, were more likely to be outborn

Table 1 Mortality, antenatal and perinatal characteristics among infants born $<29$ weeks gestation between 1998 and 2004

\begin{tabular}{|c|c|c|c|c|}
\hline Characteristic & No steroid $(n=319)$ & Any steroid $(n=2230)$ & OR $(95 \% \mathrm{Cl})$ & p Value \\
\hline Mortality $(n=2549)$ & $96(30.1)$ & $450(20.2)$ & 0.59 (0.45 to 0.76$)$ & $<0.001$ \\
\hline Maternal age, year & $28.0(23.0-32.0)$ & $30.0(25.0-34.0)$ & - & $<0.001$ \\
\hline Aboriginal ethnicity & $28(8.8)$ & $113(5.1)$ & 0.55 (0.36 to 0.85$)$ & 0.010 \\
\hline Pregnancy-induced hypertension & $21(6.6)$ & $358(16.1)$ & 2.71 (1.72 to 4.29$)$ & $<0.001$ \\
\hline Vaginal breech & $66(20.7)$ & $223(10.0)$ & 0.43 , (0.31 to 0.58$)$ & $<0.001$ \\
\hline Caesarian section in labour & $58(18.2)$ & $523(23.5)$ & $1.38(1.02$ to 1.86$)$ & 0.043 \\
\hline Born in non-tertiary centre & $140(43.9)$ & $121(5.4)$ & $0.07(0.06$ to 0.10$)$ & $<0.001$ \\
\hline Apgar score $<7$ at 5 minutes* & $127 / 304(41.8)$ & $517 / 2221(23.3)$ & $0.42(0.33$ to 0.54$)$ & $<0.001$ \\
\hline Male gender & $176(55.2)$ & $1218(54.6)$ & $0.98(0.77$ to 1.24$)$ & 0.900 \\
\hline Gestational age, weeks & $26.0(25.0-28.0)$ & $27.0(25.0-28.0)$ & - & 0.012 \\
\hline Birth weight, grams & $895(730-1090)$ & 917 (733.75-1096) & - & 0.597 \\
\hline Surfactant therapy & $273(85.6)$ & $1584(71.0)$ & 0.41 (0.30 to 0.57$)$ & $<0.001$ \\
\hline Mechanical ventilation & $305(95.6)$ & 1935 (86.8) & $0.30(0.17$ to 0.52$)$ & $<0.001$ \\
\hline Intraventricular haemorrhage grade 3 or $4^{*}$ & 53/284 (18.7) & $251 / 2130(11.8)$ & $0.58(0.42$ to 0.81$)$ & 0.001 \\
\hline Necrotising enterocolitis & $36(11.3)$ & $163(7.3)$ & 0.62 (0.42 to 0.91$)$ & 0.018 \\
\hline Length of intensive care stay, days. & $73(11-92)$ & $73(56-94)$ & - & 0.029 \\
\hline
\end{tabular}

*Denominator is number of infants examined.

Data are presented as $\mathrm{n}(\%)(\mathrm{OR}, 95 \% \mathrm{Cl})$ or median (IQR) No steroid group set as referent for OR and $95 \% \mathrm{Cl}$ calculation. OR denotes OR. 
Table 2 Mortality, antenatal and perinatal characteristics of infants born $<29$ weeks according to period of steroid exposure

\begin{tabular}{|c|c|c|c|c|c|c|c|c|c|c|c|}
\hline Characteristic & $\begin{array}{l}\text { No steroid } \\
(n=319)\end{array}$ & $\begin{array}{l}<24 \text { h steroids } \\
(n=677)\end{array}$ & OR $(95 \% \mathrm{Cl})$ & $\mathrm{p}$ Value & $\begin{array}{l}\text { Complete course } \\
(n=1281)\end{array}$ & OR $(95 \% \mathrm{Cl})$ & $p$ Value & $\begin{array}{l}\text { No steroid }+<24 \text { hrs } \\
(n=996)\end{array}$ & $\begin{array}{l}\text { Complete course + } \\
>7 \text { days }(1553)\end{array}$ & OR $(95 \% \mathrm{Cl})$ & $p$ Value \\
\hline Mortality $(n=2549)$ & $96(30.1)$ & $184(27.2)$ & $0.87(0.65$ to 1.16$)$ & 0.379 & $214(16.7)$ & $0.47(0.35$ to 0.62$)$ & $<0.001$ & $280(28.1)$ & $266(17.1)$ & 0.53 (0.44 to 0.64$)$ & $<0.001$ \\
\hline Maternal age, years & $28.0(23.0-32.0)$ & $29.0(24.0-33.0)$ & - & 0.042 & $30.0(26.0-34.0)$ & - & $<0.001$ & $28.0(23.0-33.0)$ & $30.0(25.0-34.0)$ & - & $<0.001$ \\
\hline Aboriginal ethnicity & $28(8.8)$ & $51(7.5)$ & 0.85 (0.52 to 1.37$)$ & 0.581 & $50(3.9)$ & 0.42 (0.26 to 0.68 ) & $<0.001$ & $79(7.9)$ & $62(4.0)$ & 0.48 (0.34 to 0.68$)$ & $<0.001$ \\
\hline Assisted conception & $31(9.7)$ & $66(9.7)$ & 1.00 (0.64 to 1.57$)$ & 1.000 & $197(15.4)$ & 1.69 (1.13 to 2.52$)$ & 0.012 & $97(9.7)$ & $225(14.5)$ & 1.57 (1.22 to 2.02$)$ & $<0.001$ \\
\hline $\begin{array}{l}\text { Pregnancy-induced } \\
\text { hypertension }\end{array}$ & $21(6.6)$ & $78(11.5)$ & 1.85 (1.12 to 3.05$)$ & 0.021 & $255(19.9)$ & 3.53 (2.22 to 5.61$)$ & $<0.001$ & $99(9.9)$ & $280(18.0)$ & 1.99 (1.56 to 2.55$)$ & $<0.001$ \\
\hline Chorioamnionitis* & $31 / 176(17.6)$ & $84 / 414(20.3)$ & 1.19 (0.75 to 1.88$)$ & 0.524 & $155 / 713(21.7)$ & 1.30 (0.85 to 1.99$)$ & 0.271 & $115 / 590(19.5)$ & 219/880 (24.9) & 1.37 (1.06 to 1.77$)$ & 0.018 \\
\hline Vaginal breech & $66(20.7)$ & $81(12.0)$ & 0.52 (0.36 to 0.74$)$ & $<0.001$ & $120(9.4)$ & 0.40 (0.28 to 0.55$)$ & $<0.001$ & $147(14.8)$ & $142(9.1)$ & 0.58 (0.45 to 0.74$)$ & $<0.001$ \\
\hline $\begin{array}{l}\text { Born in non-tertiary } \\
\text { centre }\end{array}$ & $140(43.9)$ & $98(14.5)$ & 0.22 (0.16 to 0.29 ) & $<0.001$ & $16(1.2)$ & 0.02 (0.01 to 0.03 ) & $<0.001$ & $238(23.9)$ & $23(1.5)$ & 0.05 (0.03 to 0.07$)$ & $<0.001$ \\
\hline $\begin{array}{l}\text { Apgar score }<7 \text { at } \\
5 \text { minutes } t\end{array}$ & $127 / 304(41.8)$ & $212 / 674(31.5)$ & 0.64 (0.48 to 0.85 ) & 0.002 & $246 / 1278$ (19.2) & 0.33 (0.25 to 0.43 ) & $<0.001$ & $339 / 978(34.7)$ & $305 / 1547(19.7)$ & 0.46 (0.39 to 0.56$)$ & $<0.001$ \\
\hline Male gender & $176(55.2)$ & $373(55.1)$ & 1.00 (0.76 to 1.30$)$ & 1.000 & $699(54.6)$ & 0.98 (0.76 to 1.25$)$ & 0.895 & $549(55.1)$ & $845(54.4)$ & 0.97 (0.83 to 1.14$)$ & 0.756 \\
\hline $\begin{array}{l}\text { Gestational age, } \\
\text { weeks }\end{array}$ & $26.0(25.0-28.0)$ & $26.0(25.0-27.0)$ & - & 0.444 & $27.0(25.0-28.0)$ & - & 0.012 & $26.0(25.0-28.0)$ & $27.0(25.0-28.0)$ & - & $<0.001$ \\
\hline Birth weight, grams & $895(730-1090)$ & $926(740-1100)$ & - & 0.449 & $900(721.5-1080.0)$ & - & 0.788 & $912.5(740.0-1095.8)$ & $914.0(731.0-1095.0)$ & - & 0.746 \\
\hline Birth weight <10th $\%$ & $27(8.5)$ & $58(8.6)$ & 1.01 (0.63 to 1.63$)$ & 0.947 & $166(13.0)$ & 1.61 (1.05 to 2.47$)$ & 0.035 & $85(8.5)$ & $187(12.0)$ & 1.47 (1.12 to 1.92$)$ & 0.006 \\
\hline Surfactant therapy & $273(85.6)$ & $529(78.1)$ & 0.60 (0.42 to 0.86$)$ & 0.007 & $885(69.1)$ & 0.38 (0.27 to 0.53$)$ & $<0.001$ & $802(80.5)$ & $1055(67.9)$ & 0.51 (0.42 to 0.62 ) & $<0.001$ \\
\hline Mechanical ventilation & 305 (95.6) & $623(92.0)$ & 0.53 (0.29 to 0.97$)$ & 0.050 & $1091(85.2)$ & 0.26 (0.15 to 0.46$)$ & $<0.001$ & $928(93.2)$ & $1312(84.5)$ & 0.40 (0.30 to 0.53$)$ & $<0.001$ \\
\hline $\begin{array}{l}\text { Duration of } \\
\text { ventilation, days }\end{array}$ & $5.5(2.0-17.0)$ & $5(2.0-13.8)$ & - & 0.315 & $6.0(2.0-20.0)$ & - & 0.222 & $5.0(2.0-15.0)$ & $6.0(2.0-19.0)$ & - & 0.023 \\
\hline $\begin{array}{l}\text { Patent ductus } \\
\text { arteriosus requiring } \\
\text { treatment }\end{array}$ & $142(44.5)$ & $325(48.0)$ & 1.15 (0.88 to 1.50$)$ & 0.336 & $512(40.0)$ & 0.83 (0.65 to 1.06$)$ & 0.157 & $467(46.9)$ & $594(38.2)$ & 0.70 (0.60 to 0.82$)$ & $<0.001$ \\
\hline $\begin{array}{l}\text { Proven systemic } \\
\text { infection }\end{array}$ & $100(31.3)$ & $218(32.2)$ & 1.04 (0.78 to 1.39$)$ & 0.844 & $498(38.9)$ & 1.39 (1.07 to 1.81$)$ & 0.015 & 318 (31.9) & $594(38.2)$ & 1.32 (1.12 to 1.56$)$ & 0.001 \\
\hline $\begin{array}{l}\text { Intraventricular } \\
\text { haemorrhage grade } 3 \\
\text { or } 4 \dagger\end{array}$ & $53 / 284(18.7)$ & $131 / 644(20.3)$ & 1.11 (0.78 to 1.59$)$ & 0.616 & $99 / 1230(8.0)$ & 0.38 (0.27 to 0.55$)$ & $<0.001$ & 184/928 (19.8) & $120 / 1486(8.1)$ & 0.36 (0.28 to 0.45$)$ & $<0.001$ \\
\hline Chronic lung disease & $84(26.3)$ & $168(24.8)$ & 0.92 (0.68 to 1.25 ) & 0.663 & $425(33.2)$ & 1.39 (1.06 to 1.83$)$ & 0.023 & $252(25.3)$ & $509(32.8)$ & 1.44 (1.21 to 1.72$)$ & $<0.001$ \\
\hline $\begin{array}{l}\text { Postnatal steroid for } \\
\text { CLD }\end{array}$ & $67(21.0)$ & $127(18.8)^{\circ}$ & $0.87(0.62$ to 1.21$)$ & 0.454 & $320(25.0)$ & 1.25 (0.93 to 1.69$)$ & 0.158 & $194(19.5)$ & $383(24.7)$ & 1.35 (1.11 to 1.64$)$ & 0.003 \\
\hline Home oxygen & $36(11.3)$ & $81(12.0)$ & 1.07 (0.70 to 1.62$)$ & 0.837 & $225(17.6)$ & 1.68 (1.15 to 2.44$)$ & 0.009 & $117(11.7)$ & $259(16.7)$ & 1.50 (1.19 to 1.90$)$ & $<0.001$ \\
\hline $\begin{array}{l}\text { Length of intensive } \\
\text { care stay, days. }\end{array}$ & 73 (11-92) & $70(27.0-92.0)$ & - & 0.919 & $75.5(59.0-96.0)$ & - & 0.002 & $71.0(16.3-92.0)$ & $75.0(59.0-96.0)$ & - & $<0.001$ \\
\hline
\end{tabular}

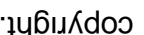

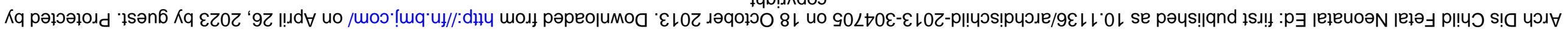


Table 3 Neurodevelopmental and anthropometric outcomes of infants born $<29$ weeks and assessed at 2-3 years of age, corrected for prematurity

\begin{tabular}{|c|c|c|c|c|c|c|c|c|c|c|c|}
\hline Characteristic & $\begin{array}{l}\text { No steroid } \\
(n=150)\end{array}$ & $\begin{array}{l}\text { Any steroid } \\
(n=1323)\end{array}$ & OR $(95 \% \mathrm{Cl})$ & $\mathrm{p}$ Value & $\begin{array}{l}\text { Complete course } \\
(n=792)\end{array}$ & OR $(95 \% \mathrm{Cl})$ & $\mathrm{p}$ Value & $\begin{array}{l}\text { No steroid }+<24 \mathrm{~h} \\
(\mathrm{n}=511)\end{array}$ & $\begin{array}{l}\text { Complete course }+ \\
>7 \text { days }(\mathrm{n}=962)\end{array}$ & $\begin{array}{l}\text { OR or mean } \\
\text { difference }\end{array}$ & $\mathrm{p}$ Value \\
\hline $\begin{array}{l}\text { Postnatal age at } \\
\text { assessment, months }\end{array}$ & $35.8(27.7-37.0)$ & $35.4(30.8-36.7)$ & - & 0.346 & $35.6(32.3-36.7)$ & - & 0.514 & $35.4(28.6-36.7)$ & $35.5(31.1-36.8)$ & - & 0.435 \\
\hline \multicolumn{12}{|c|}{ Functional disability $(n=1472)^{*}$} \\
\hline None/minimal & $97 / 150(64.7)$ & $923 / 1322(69.8)$ & 1.26 (0.89 to 1.80$)$ & 0.230 & $554 / 791(70.0)$ & $1.28(0.88$ to 1.85$)$ & 0.227 & 349/511 (68.3) & $671 / 961(69.8)$ & $1.07(0.85$ to 1.35$)$ & 0.586 \\
\hline Mild & $21 / 150(14.0)$ & $191 / 1322(14.4)$ & $1.04(0.64$ to 1.69$)$ & 0.980 & 108/791 (13.7) & 0.97 (0.59 to 1.61$)$ & 0.987 & $76 / 511(14.9)$ & 136/961 (14.2) & 0.94 (0.70 to 1.28$)$ & 0.766 \\
\hline Moderate & $17 / 150(11.3)$ & 127/1322(9.6) & $0.83(0.49$ to 1.42$)$ & 0.596 & $81 / 791$ (10.2) & $0.89(0.51$ to 1.55$)$ & 0.798 & 46/511 (9.0) & 98/961 (10.2) & 1.15 (0.79 to 1.66$)$ & 0.520 \\
\hline Severe & 15/150 (10.0) & $81 / 1322(6.1)$ & $0.59(0.33$ to 1.05$)$ & 0.100 & 48/791 (6.1) & $0.58(0.32$ to 1.07$)$ & 0.112 & 40/511 (7.8) & $56 / 961(5.8)$ & 0.73 (0.48 to 1.11$)$ & 0.171 \\
\hline Moderate to severe & $32 / 150$ (21.3) & 208/1322 (15.7) & $0.69(0.45$ to 1.05$)$ & 0.101 & 129/791 (16.3) & $0.72(0.47$ to 1.11$)$ & 0.168 & 86/511 (16.8) & 154/961 (16.0) & $0.94(0.71$ to 1.26$)$ & 0.746 \\
\hline \multicolumn{12}{|c|}{ Developmental delay (GQ/MDI) $(\mathrm{n}=1286)^{*}$} \\
\hline$-1 S D$ to $-2 S D$ & $11 / 131(8.4)$ & 73/1155 (6.3) & $0.74(0.38$ to 1.43$)$ & 0.468 & $47 / 699(6.7)$ & $0.79(0.40$ to 1.56$)$ & 0.614 & 28/449 (6.2) & $56 / 837(6.7)$ & 1.08 (0.67 to 1.72$)$ & 0.845 \\
\hline$<-2$ SD & $12 / 131(9.2)$ & $56 / 1155(4.8)$ & $0.51(0.26$ to 0.97$)$ & 0.060 & $34 / 699(4.9)$ & 0.51 (0.26 to 1.01$)$ & 0.078 & $30 / 449(6.7)$ & $38 / 837(4.5)$ & $0.66(0.41$ to 1.09$)$ & 0.132 \\
\hline $\begin{array}{l}\text { CP requiring walking aids } \\
(\mathrm{n}=1382)^{*}\end{array}$ & 9/143 (6.3) & $32 / 1239(2.6)$ & 0.39 (0.18 to 0.84$)$ & 0.041 & $17 / 743(2.3)$ & $0.38(0.15$ to 0.80$)$ & 0.031 & $20 / 479(4.2)$ & $21 / 903(2.3)$ & 0.55 (0.29 to 1.02$)$ & 0.078 \\
\hline Bilateral blindness & $0(0.0)$ & $7(0.5)$ & 1.59 (0.09 to 28.16$)$ & 1.000 & $3(0.4)$ & 1.14 (0.06 to 22.81$)$ & $>0.999$ & $4(0.8)$ & $3(0.3)$ & 0.40 (0.09 to 1.78$)$ & 0.245 \\
\hline Bilateral hearing loss & $6(4.0)$ & $46(3.5)$ & $0.86(0.36$ to 2.06$)$ & 0.924 & $28(3.5)$ & $0.88(0.36$ to 2.16$)$ & 0.967 & $21(4.1)$ & $31(3.2)$ & $0.78(0.44$ to 1.37$)$ & 0.465 \\
\hline Weight, kg & $13.3(12.0-14.8)$ & $13.5(12.1-15.0)$ & - & 0.419 & $13.5(12.0-15.0)$ & - & 0.688 & $13.5(12.2-15.0)$ & $13.5(12.0-15.0)$ & - & 0.252 \\
\hline $\begin{array}{l}\text { Weight }<10 \text { th percentile } \\
(n=1373)^{*}\end{array}$ & $33 / 138(23.9)$ & 269/1235 (21.8) & 0.89 (0.59 to 1.34$)$ & 0.642 & $168 / 739(22.7)$ & 0.94 (0.61 to 1.44$)$ & 0.848 & $101 / 477(21.2)$ & 201/896 (22.4) & $1.08(0.82$ to 1.41$)$ & 0.640 \\
\hline Height, $\mathrm{cm}$ & $94.0(89.0-97.2)$ & $93.2(89.4-97.0)$ & - & 0.869 & $93.5(89.4-97.0)$ & - & 0.856 & 93.5 (89.5-97.4) & $93.2(89.2-97.0)$ & - & 0.476 \\
\hline $\begin{array}{l}\text { Height }<10 \text { th percentile } \\
(n=1271)^{*}\end{array}$ & $17 / 127(13.4)$ & 149/1144 (13.0) & $0.97(0.57$ to 1.66$)$ & 0.981 & 95/691 (13.7) & $1.03(0.59$ to 1.80$)$ & 0.975 & $56 / 434(12.9)$ & 110/837 (13.1) & 1.02 (0.72 to 1.44$)$ & 0.974 \\
\hline Head circumference, $\mathrm{cm}$ & $49.0(47.5-50.1)$ & $49.0(48.0-50.5)$ & - & 0.296 & $49.0(48.0-50.5)$ & - & 0.257 & $49.0(48.0-50.5)$ & $49.0(47.9-50.5)$ & - & 0.914 \\
\hline $\begin{array}{l}\text { HC <10th percentile } \\
(n=1334)^{*}\end{array}$ & $35 / 138(25.4)$ & 274/1196 (22.9) & 0.87 (0.58 to 1.31$)$ & 0.589 & $167 / 713(23.4)$ & $0.90(0.59$ to 1.37$)$ & 0.703 & $103 / 469(22.0)$ & 206/865 (23.8) & 1.11 (0.85to 1.45) & 0.485 \\
\hline
\end{tabular}


(43.9\% vs $5.4 \%, \mathrm{p}<0.001)$ and were more likely to be of aboriginal ethnicity $(8.8 \%$ vs $5.1 \%, p=0.010)$. Mothers of infants with any steroid exposure had higher rates of pregnancy-induced hypertension (OR 2.71, 95\% CI 1.72 to $4.29, \mathrm{p}<0.001$ ) and were more likely to be older (median age 30 vs 28 years, $\mathrm{p}<0.001$ ) (table 1 ). There was no significant difference in antenatal steroid exposure for primiparous pregnancies $(p=0.22)$, multiple pregnancies $(p=0.18)$, exposure to chorioamnionitis $(p=0.1)$, patent ductus arteriosus $(p=0.29)$, retinopathy of prematurity grade 3 or $4(\mathrm{p}=0.98)$, duration of ventilation $(p=0.85)$, CLD $(0.16)$ and postnatal steroid use $(p=0.5)$.

\section{Mortality and major neonatal morbidities}

For infants receiving any steroid coverage, mortality rates were significantly lower $(30.1 \%$ vs $20.2 \%$, OR $0.59,95 \%$ CI 0.45 to $0.76 ; \mathrm{p}<0.001$ ) and IVH was significantly less likely (OR 0.58 , $95 \%$ CI 0.42 to $0.81, \mathrm{p}=0.001$ ), as was NEC (OR $0.62,95 \%$ CI 0.42 to $0.91, p=0.018$ ). Furthermore, steroid exposure was associated with a reduced need for surfactant therapy (OR 0.41, $95 \%$ CI 0.30 to $0.57, \mathrm{p}<0.001)$ and mechanical ventilation (OR $0.30,95 \%$ CI 0.17 to 0.52 ; p <0.001) (table 1 ).

\section{Duration of steroid exposure}

Subgroup analysis comparing incomplete $(<24 \mathrm{~h})$ steroid exposure to no steroid exposure revealed differences in mortality and rates of perinatal morbidities were not statistically significant (table 2). Significantly lower mortality rates, decreased NEC and $\mathrm{IVH}$, and decreased need for surfactant and mechanical ventilation therapy were seen only with exposure to a complete course of steroids (table 2). Complete steroid coverage was associated with significantly lower birth weight and smaller head circumference $(p=0.035$ and $p=0.046$, respectively), higher likelihood of CLD (OR 1.39, 95\% CI 1.06 to $1.83, \mathrm{p}=0.023$ ) and longer hospital stay $(75.5$ vs 73 days, $\mathrm{p}=0.002)$. No steroid coverage was associated with reduced rates of systemic infection $(31.3 \%$ vs $38.9 \%, p=0.015$ ) compared with complete coverage. Further analysis was performed according to subgroupings of none or $<24$ h exposure versus a complete course of steroids given $>7$ days prior to delivery. This revealed similar trends in terms of mortality and morbidities. A complete course of steroids given $48 \mathrm{~h}$ to $>7$ days prior to delivery significantly lowered mortality (OR 0.53 , 95\% CI 0.44 to $0.64, \mathrm{p}<0.001$ ). This exposure group was also associated with lower likelihood of surfactant therapy, mechanical ventilation and IVH, but increased incidence of proven systemic infection and CLD and smaller anthropomorphic measurements (table 2).

Adjustment for confounding factors by multivariate logistic regression analysis revealed the risk of mortality to be significantly higher with incomplete or no steroid coverage (Adjusted OR $1.874,95 \%$ CI 1.522 to 2.306 ; $\mathrm{p}<0.001$ ); this association continued to be significant within gestational age subgroups (table 2). Significant factors predictive of mortality included male gender, early gestational age (22-26 weeks) and small for gestational age (SGA). Hypertensive disease of pregnancy appeared to reduce mortality risk (adjusted OR 0.643, CI 95\% 0.447 to $0.924, \mathrm{p}=0.017$ ) (table 2 ).

\section{Long-term neurodevelopmental outcomes}

Overall, long-term neurodevelopmental outcomes were not significantly different between infants receiving no steroids compared with any steroid exposure (table 3). Any exposure to steroids was associated with decreased likelihood of moderate CP compared with no exposure (OR 0.39, 95\% CI 0.18 to $0.84, p=0.041)$. However, when the combined groups of no
Table 4 Multiple logistic regression model to determine independent factors associated with mortality among premature infants born $<29$ weeks

\begin{tabular}{|c|c|c|}
\hline Variable & $\mathrm{OR}, 95 \% \mathrm{Cl}$ & p Value \\
\hline $\begin{array}{l}\text { Antenatal steroids: none }+<24 \text { h vs complete } \\
\text { and }>7 \text { days coverage }\end{array}$ & $1.874(1.522$ to 2.306$)$ & $<0.001$ \\
\hline 22-26 weeks & 1.936 (1.527 to 2.454$)$ & $<0.001$ \\
\hline 27-28 weeks & $1.632(1.059-2.515)$ & 0.026 \\
\hline \multicolumn{3}{|l|}{ Maternal age } \\
\hline$<20$ years & $1.172(0.784$ to 1.751$)$ & 0.439 \\
\hline$\geqq 35$ years & $0.982(0.761$ to 1.269$)$ & 0.892 \\
\hline \multicolumn{3}{|l|}{ Birth weight percentiles } \\
\hline SGA vs AGA & $2.874(2.029$ to 4.073$)$ & $<0.001$ \\
\hline LGA vs AGA & $1.127(0.736$ to 1.728$)$ & $<0.001$ \\
\hline \multicolumn{3}{|l|}{ Gestational age (weeks): } \\
\hline $22-26$ weeks vs $27-28$ weeks subgroup & 6.884 (5.395 to 8.784$)$ & $<0.001$ \\
\hline Hypertensive disease of pregnancy & $0.643(0.447$ to 0.924$)$ & 0.017 \\
\hline Assisted conception & $1.129(0.829$ to 1.537$)$ & 0.442 \\
\hline Male vs female & $1.320(1.072$ to 1.626$)$ & 0.009 \\
\hline Outborn vs inborn & $0.986(0.693$ to 1.403$)$ & 0.939 \\
\hline \multicolumn{3}{|c|}{$\begin{array}{l}\text { In vitro fertilisation includes gamete intrafallopian transfer, zygote intrafallopian } \\
\text { transfer, intracytoplasmic sperm injection, etc. Hyperovulation includes any hormone } \\
\text { therapy used to stimulate ovulation. } \\
\text { Values are OR (95\% CI). Infants who did not receive steroids and those with } \\
<24 \mathrm{~h} \text { before delivery were set as referent group. Analysis was performed for whole } \\
22-28 \text { weeks cohort and then stratified for the two subgroups of } 22-26 \text { weeks and } \\
27-28 \text { weeks gestational age. } \\
\text { AGA, appropriate for gestational age; LGA, large for gestational age ( }>90 \text { th } \\
\text { percentile); SGA, small for gestational age (<10th percentile). }\end{array}$} \\
\hline
\end{tabular}

steroids and less than $24 \mathrm{~h}$ was compared to the combined group of complete course or greater than 7 days, a $1.9 \%$ decrease in moderate CP was found but this did not reach statistical significance $(p=0.078)$. Multiple logistic regression analysis for factors predictive of adverse long-term outcomes revealed that antenatal steroids had no significant effect on long-term moderate/severe FD after adjustment for confounders (adjusted OR $1.056,95 \%$ CI 0.785 to $1.420, p=0.720)$. Other factors found to be significant for moderate/severe FD were male gender (adjusted OR 1.853, 95\% CI 1.382 to $2.485, \mathrm{p}<0.001$ ), 22-26 weeks gestational age (adjusted OR 2.365, 95\% CI 1.774 to $3.151, \mathrm{p}<0.001$ ) and SGA (adjusted OR 2.160, 95\% CI 1.436 to $3.249, \mathrm{p}<0.001$ ) (table 4 ).

\section{Gestational age outcomes}

Subgroup analysis of the cohort by gestational age was performed, excluding five infants born at 22 weeks that did not survive hospital discharge. A significant reduction in mortality was evident from 24 to 27 weeks gestational age with a complete course of antenatal steroids, compared with those who received none or an incomplete course (table 5). Decreased mortality in infants born at 23 weeks and 28 weeks was observed, but did not reach statistical significance $(p=0.239$ and $p=0.448$, respectively). Severe IVH was significantly lower at 24-28 weeks gestational age in infants receiving a complete course of antental steroids (table 5). CLD was more likely in infants receiving a complete course of steroids across all gestational ages, but this did not reach statistical signfiicance, except at 24 weeks $(p=0.039)$ and 26 weeks gestational age $(p<0.001)$. No significant differences were observed between treatment groups for long-term neurodevelopmental outcomes (table 5).

\section{DISCUSSION}

It has previously been demonstrated that only a complete course of steroids confers survival benefit and reduction in IVH for 
Table 5 Mortality, short-term neonatal morbidities and long-term neurodevelopmental outcomes among infants born $<29$ weeks, by gestational age

$$
\text { Mortality and short-term morbidities }
$$

\begin{tabular}{lll}
\hline Mortality CLD & IVH grade 3 or 4*
\end{tabular}

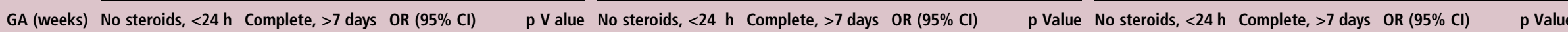

\begin{tabular}{|c|c|c|c|c|c|c|c|c|c|c|c|c|}
\hline $23 n=99$ & $47(74.6)$ & $22(61.1)$ & $0.54(0.22$ to 1.29$)$ & 0.239 & $15(23.8)$ & $13(36.1)$ & 1.81 (0.74 to 4.42$)$ & 0.282 & $14 / 48(29.2)$ & $12 / 33(36.4)$ & $1.39(0.54$ to 3.57$)$ & 0.660 \\
\hline $24 n=276$ & $71(60.7)$ & $70(44.0)$ & 0.51 (0.31 to 0.83$)$ & 0.009 & $37(31.6)$ & $71(44.7)$ & 1.74 (1.06 to 2.88 ) & 0.039 & $36 / 101(35.6)$ & $25 / 144(17.4)$ & $0.38(0.21$ to 0.69$)$ & 0.002 \\
\hline $25 n=375$ & $64(43.0)$ & $69(30.5)$ & 0.58 (0.38 to 0.90$)$ & 0.019 & $52(34.9)$ & $89(39.4)$ & 1.21 (0.79 to 1.86$)$ & 0.443 & 40/137 (29.2) & $26 / 207$ (12.6) & 0.35 (0.20 to 0.60$)$ & $<0.001$ \\
\hline $26 n=521$ & $50(24.8)$ & $54(16.9)$ & $0.62(0.40$ to 0.96$)$ & 0.039 & $60(29.7)$ & $147(46.1)$ & 2.02 (1.39 to 2.94$)$ & $<0.001$ & 48/189 (25.4) & $17 / 306(5.6)$ & $0.17(0.10$ to 0.31$)$ & $<0.00$ \\
\hline $27 n=557$ & $26(12.5)$ & $25(7.2)$ & 0.54 (0.30 to 0.96$)$ & 0.050 & $50(24.00$ & $107(30.7)$ & $1.40(0.95$ to 2.07$)$ & 0.114 & $26 / 204(12.7)$ & $24 / 343(7.0)$ & 0.52 (0.29 to 0.92$)$ & 0.03 \\
\hline $28 n=716$ & $18(7.1)$ & $25(5.4)$ & 0.75 (0.40 to 1.39$)$ & 0.448 & $38(15.0)$ & $82(17.7)$ & $1.22(0.80$ to 1.85$)$ & 0.414 & 20/247 (8.1) & $16 / 453(3.5)$ & $0.42(0.21$ to 0.82$)$ & 0.01 \\
\hline
\end{tabular}

Long-term outcomes

Mod/severe FD*

Developmental delay $-1-2 \mathrm{SD}^{*}$

Developmental delay $-2-3 \mathrm{SD}^{*}$

GA (weeks) No steroids, $<24 \mathrm{~h}$ Complete, $>7$ days OR $(95 \% \mathrm{Cl}) \quad$ p Value No steroids, $<24 \mathrm{~h}$ Complete, $>7$ days OR $(95 \% \mathrm{Cl})$

p Value No steroids, $<24 \mathrm{~h}$ Complete, $>7$ days OR $(95 \% \mathrm{Cl})$ p Value

$24 n=117$

$10(25.0)$

$28(36.4)$

$0.37(0.06$ to 2.09$) \quad 0.402$

$3 / 35(8.6)$

$6 / 68(8.8)$

$1.03(0.24$ to 4.40$)>0.999-4 / 35(11.4)$

$1 / 8(12.5)$

$1.29(0.07$ to 24.38$)>0.999$

$25 n=206$

$17(23.0)$

$23(17.4)$

$1.41(0.70$ to 2.86$) \quad 0.434$

$5 / 64(7.8)$

$10 / 110(9.1)$

$\begin{array}{rrrr}1.18(0.38 \text { to } 3.62) & 0.992 & 10 / 64(15.6)\end{array}$

$11 / 68(16.2)$

1.50 (0.44 to 5.09$) \quad 0.725$

$1.08(0.59$ to 1.97$) \quad 0.925 \quad 8 / 99(8.1)$

$14 / 169(8.3)$

$1.03(0.42$ to 2.54$) \quad 0.863 \quad 6 / 99(6.1)$

$7 / 110(6.4)$

$0.37(0.13$ to 1.02$) \quad 0.086$

$27 n=365$

$16(10.3)$

$27 / 244(11.1)$

0.81 (0.42 to 1.57$) \quad 0.647$

$4 / 102(3.9)$

$14 / 222(6.3)$

1.65 (0.53 to 5.14$) \quad 0.542 \quad 5 / 102(4.9)$

$7 / 222(3.2)$

$0.77(0.26$ to 2.29$) \quad 0.852$

*Denominator is the number of infants examined

Data are presented as $\mathrm{n}(\%)(\mathrm{OR}, 95 \%, \mathrm{Cl})$ or median (IQR). No steroid $+<24 \mathrm{~h}$ steroid infant group set as referent for $\mathrm{OR}$ and $95 \% \mathrm{Cl}$ calculation.

$\mathrm{CLD}$, chronic lung disease; FD, functional disability; IVH, intraventricular haemorrhage. 
infants born 23-26 weeks; a benefit that persists even if administration of steroids is more than 7 days from delivery. ${ }^{20}$ Our data, in line with existing literature, shows that only infants who received a full course of steroids more than $48 \mathrm{~h}$ prior to delivery obtained the benefits of steroids. These benefits were not gained by infants who received no steroids or an incomplete course. Our results add impetus to the argument for prompt commencement of antenatal steroids when premature delivery is likely, to maximise the likelihood of a full course of steroids being received prior to delivery.

Previous cohort studies showed that steroid exposure made no significant difference to rates of CLD, the need for respiratory support and length of hospital stay. ${ }^{3} 7$ By contrast, our study showed that full steroid exposure was associated with a reduction in the need for surfactant and mechanical ventilation. However, infants in this cohort that received a complete steroid course were more likely to record anthropomorphic measurements in the lower percentiles, increased rates of CLD and longer hospital stays.

Previous research demonstrates that steroid exposure is associated with less developmental delay at 1 and 3 years of follow-up ${ }^{21} 22$ and lower incidence of CP after steroid exposure. ${ }^{22}$ Our results showed that complete steroid exposure may be associated with a reduced likelihood of moderate CP in premature infants at 2-3 years of follow-up. However, we found no overall significant differences in long-term neurodevelopment with steroid exposure. However, because the number of neonates who received no steroids was small, this difference may not necessarily hold true if the numbers had been greater. With the significant survival and short-term morbidity that antenatal steroids provide, it is unlikely that a study would occur where a comparison of no steroids, as against steroid exposure, would occur in the current climate. However, future studies aimed at evaluating whether two doses of betamethasone (4 doses of dexamethasone) in $24 \mathrm{~h}$ confers the same benefit as 2 doses of betamethasone (4 doses of dexamethasone) after $48 \mathrm{~h}$ would be beneficial.

In utero inflammation is implicated as a risk factor for premature delivery. ${ }^{23}$ In the presence of chorioamnionitis, the administration of a complete course of antenatal corticosteroids is associated with decreased risk of IVH and CP in premature infants. ${ }^{24}$ We found lower rates of IVH and moderate CP with steroid coverage in our cohort study, consistent with previous studies.

The observed improvement in survival from 24 weeks to 27 weeks gestational age with complete steroid coverage, and the significant reduction in severe IVH from 24 weeks to 28 weeks, is consistent with the literature. Cohorts stratified for gestational age previously showed reduced mortality from 22 weeks to 27 weeks gestational age. ${ }^{7}$ Although mortality was not shown to be significantly reduced at 23 weeks gestational age with complete steroid exposure, the small sample of 23-week infants in our study may have been insufficient for measurement of a significant effect; it is possible that a survival advantage is still afforded by steroids at exteremely premtaure ages. ${ }^{7}$

Strengths of our study include the fact that it was a geographically defined population-based cohort study, which means that results are unlikley to be biased by centre-based information. The standardised collection of data by the NICUs Data Collection and Follow-up Data Collection also ensured consistently collected data for the 6-year epoch. However, this study in itself is retrospective in nature. There were relatively small sample sizes for gestational ages of 22-25 weeks and missing parameters for $12 \%$ of the follow-up cohort included at longterm assessment. These limitations raise the possibility that other significant effects of antenatal steroid exposure on longterm outcomes may not have been detected in our study population. Further analysis using on-going data collection could examine the cohort's long-term outcomes at 5 years and 10 years, determining the effects of antenatal steroid exposure on later learning and development.

This study demonstrates a clear benefit derived from steroid coverage across gestational ages. The clinical application of results from this large-scale cohort study pertains to preliminary counselling of parents of premature infants. In the context of decisions regarding intensive care treatment, the gestational age tables generated could be used in discussion of the likelihood of survival, perinatal complications and long-term FD given exposure to steroids. Furthermore, outcome data from such cohort studies could eventually be used to formulate survival prediction equations that include prenatally available parameters, such as steroid exposure. ${ }^{25}$

\section{CONCLUSIONS}

Within this Australian cohort of exteremly premature infants, there was significant improvement in hospital survival and reduced NEC and IVH with exposure to antenatal steroids. This advantage was afforded only by exposure to a complete steroid course. Significant survival benefit and decreased incidence of IVH was seen from 24 weeks to 28 weeks gestational age. Antenatal steroids were associated with a decreased risk of moderate CP. Long-term neurodevelopmental outcomes in premature infants at 2-3 years follow-up were not significantly affected by antenatal steroid exposure.

Acknowledgements The authors thank the Directors, the NICUS members and the audit officers of all tertiary units in supporting this collaborative study: NICUS, Dr Jennifer Bowen (Chairperson), Barbara Bajuk (Coordinator); Canberra Hospital, A/Prof Zsuzsoka Kecskés (Director), A/Prof Alison Kent, John Edwards; John Hunter Children's Hospital, Dr Chris Wake (Director), Lynne Cruden; Royal Prince Alfred Hospital, A/Prof Nick Evans (Director), Dr Phil Beeby, A/Prof David Osborn, Shelley Reid; Liverpool Hospital, Dr Robert Guaran (Director), Dr lan Callander, Kathryn Medlin, Sara Wilson; Nepean Hospital, Dr Lyn Downe (Director), Mee Fong Chin; The Children's Hospital at Westmead, Prof Nadia Badawi (Director), Robert Halliday, Caroline Karskens; Royal North Shore Hospital, Dr Mary Paradisis (Acting Director), A/Prof Martin Kluckow, Sara Sedgley; Sydney Children's Hospital, Dr Andrew Numa (Director), Dr Gary Williams, Janelle Young; Westmead Hospital, Dr Mark Tracy (Acting Director), Jane Baird; and Royal Hospital for Women, A/Prof Kei Lui (Director), Dr Julee Oei, Diane Cameron. We also thank the babies and their families, the nursing and midwifery, obstetric and medical records staff of the obstetric and children's hospitals in NSW and the ACT.

Contributors DW helped design the study, drafted the initial manuscript, assisted in the statistical analysis and approved the final manuscript as submitted. MEA-L assisted with the statistical analyses, reviewed and revised the manuscript and approved the final manuscript as submitted. ALK: conceptualised and designed the study, coordinated the analysis, critically reviewed the manuscript and approved the final manuscript as submitted.

Competing interests None.

Ethics approval ACT Human Research Ethics Committee.

Provenance and peer review Not commissioned; externally peer reviewed.

\section{REFERENCES}

1 Liggins GC, Howie RN. A controlled trial of antepartum glucocorticoid treatment for prevention of the respiratory distress syndrome in premature infants. Pediatrics 1972;50:515-25.

2 Mwansa-Kambafwile J, Cousens S, Hansen T, et al. Antenatal steroids in preterm labour for the prevention of neonatal deaths due to complications of preterm birth. Int J Epidemiol 2010;39:i122-33.

3 Roberts D, Dalziel SR. Antenatal corticosteroids for accelerating fetal lung maturation for women at risk of preterm birth. Cochrane Database Syst Rev 2006 (3):CD004454.

4 Chiswick M. Infants of borderline viability: Ethical and clinical considerations. Semin Fetal Neonatal Med 2008;13:8-15.

5 Doyle LW, Roberts G, Anderson PJ, et al. Outcomes at age 2 years of Infants $<28$ weeks' gestational age born in Victoria in 2005. J Pediatr 2010;156:49-53. 
6 Itabashi K, Horiuchi T, Kusuda S, et al. Mortality rates for extremely low birth weight infants born in Japan in 2005. Pediatrics 2009;123:445-50.

7 Manktelow BN, Lal MK, Field DJ, et al. Antenatal corticosteroids and neonatal outcomes according to gestational age: a cohort study. Arch Dis Child Fetal Neonatal Ed 2010;95:F95-8.

8 Mori R, Kusuda S, Fujimura M. Antenatal corticosteroids promote surival of extremely preterm infants born at 22-23 weeks of gestation. J Pediatr 2011;159:110-14

9 MacArthur B, Howie RN, Dezoete J, et al. School progress and cognitive development of 6 -year-old children whose mothers were treated antenatally with betamethasone. Pediatrics 1982;70:99-105.

10 Doyle LW, Kitchen WH, Ford GW, et al. Antenatal steroid therapy and 5-year outcome of extremely low birth weight infants. Obstet Gynecol 1989;73:743-6.

11 Smolders-de Haas H, Neuvel J, Schmand B, et al. Physical development and medical history of children who were treated antenatally with corticosteroids to prevent respiratory distress syndrome: a 10- to 12-year follow-up. Pediatrics 1990;86:65-70.

12 Doyle LW, Ford GW, Rickards AL, et al. Antenatal corticosteroids and outcome at 14 years of age in chidlren with birthweight less than 1501 grams. Pediatrics 2000;106:E2.

13 Bajuk B. Validation of the neonatal intensive care units' data collection. Proceedings of the 5th Annual Congress of Perinatal Society of Australia and New Zealand, 2001:55.

14 Bell MJ, Ternberg JL, Feigin RD, et al. Neonatal necrotizing enterocolitis: therapeutic decisions based upon clinical staging. Ann Surg 1978;187:1-7.

15 Luig M, Lui K, Group NaAN. Epidemiology of necrotizing entercolitis_Part I: changing regional trends in extremely preterm infants over 14 years. J Paediatr Child Health 2005;41:169-73.
16 Papile L, Burstein J, Burstein R, et al. Incidence and evolution of subependymal and intraventricular hemorrhage: a study of infants with birth weights less than 1,500 gm. J Pediatr 1978:92:529-34.

17 An International classification of retinopathy of prematurity. Paediatrics 1984:74:127-33.

18 Kent AL, Wright IMR, Abdel-Latif ME, for New South Wales and Australian Capital Territory Neonatal Intensive Care Units Audit Group. Mortality and adverse neurologic outcomes are greater in preterm male infants. Pediatrics 2012;129:124-31.

19 Perneger T. What's wrong with Bonferroni adjustments. BMJ 1998;316:1236-8.

20 Chawla S, Natarajan G, Rane S, et al. Outcomes of extremely low birth weight infants with varying doses and intervals of antenatal steroid exposure. J Perinat Med 2010;38:419-23.

21 Kiechl-Kohlendorfer U, Ralser E, Peglow UP, et al. Adverse neurological outcomes in preterm infants: risk factor profiles for different gestational ages. Acta Paediatr 2009;98:792-6.

22 Amorim MM, Santos LC, Faundes A. Corticosteroid therapy for prevention of respiratory distress syndrome in severe preeclampsia. Am J Obstet Gynecol 1999:180:1283-8.

23 Romero R, Espinoza J, Goncalves L, et al. The role of inflammation and infection in preterm birth. Semin Reprod Med 2007;25:21-39.

24 Kent $\mathrm{AL}$, Lomas $\mathrm{F}$, Hurrion $\mathrm{E}$, et al. Antenatal steroids may reduce adverse neurological outcome following chorioamnionitis: neurodevelopmental outcome and chorioamnionitis in premature infants. J Paaediatr Child Health 2005;41:186-90.

25 Schenone $\mathrm{MH}$, Aguin $\mathrm{E}$, Li Y, et al. Prenatal prediction of neonatal survival at the borderline viability. J Matern Fetal Neonatal Med 2010;23:1413-8. 